\title{
PROFISSIONALIDADE DOCENTE PARA O TRABALHO PEDAGÓGICO EM AMBIENTES DIGITAIS NO ENSINO E APRENDIZAGEM DE LÍNGUAS
}

\author{
TEACHING PROFESSIONALITY FOR PEDAGOGICAL WORK IN \\ DIGITAL ENVIRONMENTS IN LANGUAGE TEACHING AND \\ LEARNING
}

\begin{abstract}
Manoela Oliveira de Souza Santana ${ }^{1}$
Resumo: O presente artigo tratará das implicações da formação docente, numa perspectiva autoetnográfica e etnográfica, para a efetividade do ensino e aprendizagem de línguas em ambientes digitais. Tem-se como objetivo compreender como saberes e fazeres, referentes a esse processo, refletem empreendimentos na formação docente. Por meio da pesquisa-formação, em uma abordagem qualitativa, descritiva e interpretativista, inscrita na agenda da Línguística Aplicada, sinaliza-se nos resultados da pesquisa a necessidade de investimento no web currículo em práticas com os multiletramentos a fim de que tecnologias contribuam para o pensar e agir tecnológicos em um processo de aprendizagem crítica de línguas alicerçado no ser-tecnologicamente-no-mundo.
\end{abstract}

Palavras-chave: Profissionalidade; Ambientes Digitais; Ensino e Aprendizagem de Línguas.

\begin{abstract}
This article will deal with the implications of teacher training, in an autoetnographic and ethnographic perspective, for the effectiveness of language teaching and learning in digital environments. The objective is to understand how knowledge and practices related to this process reflect undertakings in teacher education. Through research-training, in a qualitative, descriptive and interpretive approach, inscribed on the Applied Linguistics agenda, the search results indicate the need to invest in the web curriculum in practices with multi-tools in order for technologies to contribute to the technological thinking and acting in a critical language learning process based on being-technologically-in-the-world.

Keywords: Professionality; Digital Environments; Language Teaching and Learning.
\end{abstract}

\section{Introdução.}

Por ofício, vocação, missão, escolha, dom, entre outras tantas possíveis explicações, sou professora. Gosto de dizer isso fazendo uma alusão ao conto Felicidade Clandestina de Clarice Lispector em que a narradora diz "Criava as mais falsas dificuldades para aquela coisa clandestina que era a felicidade. A felicidade sempre ia ser clandestina para mim. Parece que eu já pressentia. Como demorei!" (CLARICE LISPECTOR, 1998, p. 07). Destarte, num tom clandestino, cada vez que preciso pensar e falar sobre a minha identidade profissional, sou tomada por uma felicidade simples e, serenamente, particular.

Há 22 anos, tenho vivenciado essa sensação. Posso citar aqui, algumas experiências significativas que me trouxeram êxtase e me tornaram amante da docência: o momento em que alfabetizei crianças, o período em que fui tutora de um Curso de Licenciatura em Letras e as mediações de pesquisas científicas em um curso de educação profissional, além da produção da minha tese de Doutorado pelo fato de esta contemplar minhas experiências autoetnográficas na condição de docente e de pesquisadora.

\footnotetext{
${ }^{1}$ Doutora em Língua e Cultura - Universidade Federal da Bahia (UFBA); Docente de Língua Portuguesa do Centro Territorial de Educação Profissional do Baixo Sul; Coordenadora Pedagógica da Rede Municipal de Ensino de Gandu-BA e Pesquisadora do Núcleo de Estudos de Linguagens e Tecnologias da UFBA. Email: maneftc4@yahoo.com.br.
} 
A minha caminhada, como educadora e pesquisadora, suscitou em mim a necessidade de refletir sobre o processo de formação dos sujeitos docentes, bem como problematizá-lo. O que sabemos e agenciamos no ensino e aprendizagem de línguas em ambientes digitais reflete a nossa formação inicial e continuada para a docência e carece progressivamente de um renovo.

Houve um tempo em que satisfazia, tão somente, a formação inicial para enveredar e prosseguir na carreira do magistério. A movência a qual estamos submetidos na sociedade tecnológica digital nos convida, a todo o tempo, para entender e empreender ações referentes ao cultivo da profissionalidade docente o que implica a necessidade de aperfeiçoamento na e pelas interações com aqueles que a exercem em função do desenvolvimento das competências necessárias ao bom exercício da profissão. Integra-se a esta a condição de docente pesquisador por entender que a pesquisa impulsiona a reflexividade que está no cerne da reflexão-ação-reflexão referente à performance didática. Daí, a relevância de o educador colocar-se à disposição da pesquisa-formação.

Nesses termos, o presente artigo é resultado de uma pesquisa cujo objetivo geral consiste em compreender como saberes e fazeres no ensino e aprendizagem de línguas com tecnologias digitais refletem empreendimentos na formação docente. $\mathrm{E}$ como objetivos específicos propõe: discutir aspectos epistemológicos que referenciam a profissionalidade docente no contexto da cultura digital e em processos de pesquisaformação, bem como discernir sobre a importância do web currículo para o trabalho com os multiletramentos no ensino de línguas por meio de tecnologias digitais

Preparar-se continuamente a fim de atuar enquanto docente de línguas em interação com tecnologias digitais para aprendizagem e comunicação subjaz uma prática pedagógica a qual se vincula a um currículo crítico, que respeita a diversidade, as peculiaridades do sujeito num processo didático promotor da construção problematizadora e reflexiva do conhecimento. Então, falamos em web currículo numa interface entre o currículo escolar e as tecnologias digitais para a construção do conhecimento humanizador e crítico.

Portanto, o percurso deste artigo contemplará uma abordagem sobre a formação docente na perspectiva da profissionalidade, destacando a relevância de um trabalho pedagógico propenso à vivência dos multiletramentos no ensino $\mathrm{e}$ aprendizagem de línguas em ambientes digitais que se alie continuamente à pesquisaformação, tendo como alicerce um web currículo motivador do trabalho com tecnologias, na perspectiva do ser-tecnologicamente-no-mundo.

Estamos, para tanto, aliados à Linguística Aplicada que contempla em sua agenda pesquisas sobre a formação docente, também, quando o pesquisador é o educador e não tem, dessa forma, apenas a prática do outro como um referencial de pesquisa, mas os seus saberes e fazeres entram em cena a fim de que se possa analisar processos pedagógicos e empreender novas possiblidades de trabalho didáticos no ensino de línguas, em articulação com tecnologias digitais.

\section{Por onde andei também pude me encontrar: caminhos metodológicos.}

O referencial da pesquisa que sustenta este artigo é autoetnográfico e etnográfico. Segundo Versiani (2002), na autoetnografia, a presença de "auto" refere-se à singularidade de cada sujeito; "etno" localiza esse mesmo sujeito, parcial e pontualmente, em determinado grupo cultural. Ocorre um encontro de subjetividades construídas de modo relacional e dialógica. A autoetnografia é um espaço para a 
reflexão de nossa própria inserção social, histórica, identitária nas convivências que estabelecemos. Nela, o pesquisador é responsável pela construção da episteme, como um participante ativo com

[...] uma postura autorreflexiva (autoetnográfica), atenta à construção intersubjetiva de sua própria subjetividade, circunstanciada por trajetórias intelectuais e pessoais singulares, através de sua inserção em diferentes grupos socioculturais, afetivas e, até mesmo, casuais e contingenciais. (VERSIANI, 2002, p. 71)

A etnografia alimenta a autoetnografia. Interagir com a inferface de ambas (uma escrita sobre mim e uma escrita sobre o outro) é necessário para estudar e, assim, ter uma representação da perspectiva dos sujeitos envolvidos quanto às experiências culturais arraigadas nos contextos de vivência dos docentes, ao papel da reflexão sobre a prática e a constituição histórica do professor no processo de formação (SILVA; SILVA, 2016). Além de estudar multiletramentos no ensino e aprendizagem de línguas em ambientes digitais, com base em saberes e fazeres docentes, são pertinentes reflexão, autoconhecimento e compreensão da dimensão política inerente ao fazer pedagógico (FREIRE, 1975 e 1980).

A proposição metodológica da pesquisa que subjaz este artigo é de natureza qualitativa por tratar, a partir de dados construídos (em entrevistas sobre a formação docente e em observações de aula) na etnografia e na autoetnografia, de como o processo formacional docente interfere em suas epistemologias e ações didáticas mediante a necessidade de empreender a vivência dos multiletramentos no ensino e aprendizagem de línguas em ambientes digitais. Para tanto, serão socializadas descrições e interpretações de resultados de minha experiências pedagógicas, bem como de outros dois profissionais (LP e LI) ${ }^{2}$ num contexto de pesquisa-formação (ANDRÉ, 2002; BUENO, 2000; RAUSCH, 2012) que envolve interações em movimentos de formação docente e empreendimentos de práticas que integram o trabalho com os multiletramentos no ensino de aprendizagem de línguas em ambientes digitais.

\section{Sobre a profissionalidade docente em interface com tecnologias digitais.}

Por meio da autoetnografia e da etnografia, a motivação, o prazer, a afinidade, entre outros ingredientes necessários à efetividade da profissionalidade docente, nos unem no sentido do saber-fazer, também em ambientes digitais, um ensino e aprendizagem de línguas mais proficiente com vistas na vivência dos multiletramentos. Somam-se a esses ingredientes outras competências profissionais para ensinar, citadas por Perrenoud (2000 e 2002), a saber: organizar e dirigir situações de aprendizagem; administrar a progressão das aprendizagens; conhecer e fazer evoluir os dispositivos de diferenciação; envolver os alunos em sua aprendizagem e em seu trabalho; trabalhar em equipe; participar da administração da escola; informar e envolver os pais; enfrentar os

\footnotetext{
${ }^{2}$ LP e LI, nomes fictícios atribuídos a colegas de profissão, respetivamente, são professores de Língua Portuguesa e Língua Inglesa do Centro Territorial de Educação Profissional do Baixo Sul (CETEP do Baixo Sul). Foram grandes parceiros (conforme autorização do Comitê de Ética em julho de 2016) em uma pesquisa etnográfica e autoetnográfica que realizei para a produção da tese do Doutorado em Língua e Cultura - intitulada Um Entrelugar para os Multiletramentos no Ensino e Aprendizagem de Línguas com Tecnologias Digitais - do Programa de Pós-Graduação em Língua e Cultura da Universidade Federal da Bahia. Neste artigo, utilizarei alguns recortes do instrumental dessa pesquisa.
} 
deveres e os dilemas éticos da profissão; administrar sua própria formação contínua e utilizar novas tecnologias.

Compreendo que a garantia de todas essas competências no ambiente escolar fortalece o trabalho com os multiletramentos, uma vez que este tanto privilegia o trabalho com a multiplicidade de linguagens como com a diversidade cultural (COPE; KALANTZIS, 2000) em nível local e global (ROJO; BARBOSA, 2015). Isso porque, para que nós, docentes, vivenciemos os multiletramentos, é relevante ter um conhecimento técnico do componente curricular que iremos trabalhar, considerar as fases e experiências de vida dos educandos, contribuir para a progressão da aprendizagem, lidar com as diversidades no grupo, motivar os sujeitos discentes, participar da gestão dos arranjos produtivos nas instituições de educação, desenvolver o senso de justiça, investir na própria formação docente e contribuir com a dos colegas (PERRENOUD, 2000 e 2002). Para tanto, o professor precisa ter uma formação mínima, tanto inicial como continuada, para mediar um trabalho nessa perspectiva. Isso faz parte da construção da profissionalidade docente.

Profissionalidade docente é um termo complexo, ainda em construção, que faz referência ao que é peculiar à profissão docente ou, mais especificamente, à necessidade de recuperar as qualidades do educador em suas funções específicas (GORZONI; DAVIS, 2017). Está associada a diversos aspectos, tais como:

[...] o conhecimento profissional específico; a expressão de maneira própria de ser e atuar como docente; o desenvolvimento de uma identidade profissional construída nas ações do professor e à luz das demandas sociais internas e externas à escola; a construção de competências e o desenvolvimento de habilidades próprias do ato de ensinar conquistadas durante a formação inicial e/ou continuada e também ao longo das experiências de trabalho do professor. (GORZONI; DAVIS, 2017, p. 1.412)

Considero pertinente trazer para esse espaço o que nos diz Tardif (2002) sobre saberes docentes e formação profissional. Para ele, o educador tem grande relevância no processo educacional. A identidade, a experiência de vida, a história pessoal, a relação com os educandos e com outros sujeitos do contexto escolar implicam o saber docente. Este é caracterizado, nas palavras do autor, como social porque seus objetos são práticas sociais; por ser partilhado por um grupo - o qual adquire o saber no contexto de uma socialização profissional - com atuações e formações comuns; em função de ter um sistema que o legitima; revelar-se em relações complexas entre educando e educador, e por ser mutável no tempo conforme a cultura da sociedade e de seus poderes, das hierarquias da educação formal e informal.

Durante a atuação, o educador internaliza orientações de ação que passam a constituir sua consciência prática. Para Tardif (2002), as relações dos professores com os saberes não são estritamente cognitivas, entretanto, mediadas pela ação docente a qual oferece indicativos para se resolver problemas. $\mathrm{O}$ educador, nesse processo, constrói um saber heterogêneo proveniente do contexto de uma história de vida e de uma carreira profissional.

Destarte, ensinar consiste em aprender a ensinar progressivamente no curso da função docente com interferências significativas das experiências familiares e escolares que antecederam a formação inicial do docente por se tratar de um momento que se adquiriu representações e possíveis certezas do que é ser professor. Nesse sentido, saberes e formação docente integram história, emoção, afetividade, crença e cultura na 
transmissão do saber, considerando que o educador é um ator que protagoniza seu quefazer docente com autonomia e produz novos saberes sobre os que já possui.

A formação docente, portanto, é imprescindível, lembrando que, em termos de políticas públicas, deve haver um investimento nesse processo, ressalvando-se que o professor precisa participar da sua formação, manifestar saberes e fazeres, seus anseios e necessidades de retroalimentação de sua atividade.

Nóvoa (1997) diz que a formação e configuração do docente são cruciais para ação didática, transcendendo um espaço de aquisição de técnicas e de conhecimentos de modo a incentivar a cultura dessa atividade no contexto educacional. Há programas com essa finalidade que são frágeis, tanto conceitualmente como metodologicamente. Além disso, não se leva em conta aspectos da identidade docente, da ambiência escolar que nem sempre são comuns às dinâmicas propostas por esses programas.

É salutar valorizar uma interface entre a formação e os projetos das escolas, considerando a individualidade e a coletividade docente de modo que se estimule

[...] uma perspectiva crítico-reflexiva, que forneça aos professores os meios de um pensamento autónomo e que facilite as dinâmicas de autoformação participada. Estar em formação implica um investimento pessoal, um trabalho livre e criativo sobre os percursos e os projetos próprios, com vista à construção de uma identidade, que é também uma identidade profissional. (NÓVOA, 1997, p. 25)

Vale ressaltar que a formação não resulta da acumulação de cursos, conhecimentos ou técnicas, pois é o produto da reflexividade crítica sobre as práticas e de (re)construção contínua de uma identidade pessoal (NÓVOA, 1997). Nesse caso, como se trata do investimento na produção de saberes a partir da experiência, uma rede de (auto)formação colaborativa poderá consolidar-se como um espaço de formação mútua em que o educador, dialogicamente, educa e é educado em comunhão com os seus pares o que poderá dar corpo a um exercício autônomo da profissão docente.

\section{Quando o web currículo motiva o saber e o fazer docentes.}

Compreendo que, na condição de docentes de Língua Portuguesa e de Língua Inglesa, precisamos nos engajar e contribuir para ampliação da competência discursiva dos nossos educandos, ampliação esta que também perpassa pelas práticas discursivas digitais. Necessariamente, ajustes curriculares serão imprescindíveis nesse processo, não somente em função das inovações tecnológicas - visto que não é coerente modernizar práticas pedagógicas se permanecermos com o mesmo paradigma educacional - mas da necessidade de se implementar o ensino e aprendizagem de línguas para a formação crítica e ativa dos sujeitos.

Nesses termos, é pertinente transcender um referencial tradicional de currículo e ter como alicerce no processo ensino e aprendizagem de línguas uma proposta curricular em que teorias curriculares críticas e pós-críticas se tocam. Essa proposta, em interface com as tecnologias digitais, apresenta o web currículo como um alicerce significativo para se empreender esse processo.

Silva (2010), oportunamente, esclarece que currículo não é conjunto de conteúdos; sua construção resulta de um alicerce teórico sobre práticas pedagógicas e do entendimento de conflitos culturais dos diferentes sujeitos que o elaboram. O currículo integra, portanto, múltiplas redes de subjetividades daqueles que movem a ambiência 
escolar e resulta de uma seleção de um universo mais amplo de conhecimentos e saberes.

Esse alicerce teórico pode integrar teorias tradicionais as quais centram o interesse no ensino, na aprendizagem, avaliação, metodologia, planejamento, apresentando-se como neutras. Valorizam o saber considerado hegemônico e, essencialmente, "o quê" ensinar.

As teorias críticas se ocupam do "porquê dos eventos", focam em processos como: ideologia, reprodução cultural e social, poder, classe social, capitalismo, relações sociais de produção, conscientização, emancipação, currículo oculto, resistência, abordando que nenhuma teoria é desinteressada, portanto, encontra-se implicada em relações de poder.

Já as pós-críticas, tratam da relação entre saber, identidade e poder, cuidando da alteridade, diferença, subjetividade, significação e discurso, saber e poder, representação e cultura. Assim, reconhecem que o poder é descentralizado e as formas de culturas de diferentes grupos sociais se colocam sempre como problematizadoras a fim de compreender os processos de dominação. "[...]as teorias pós-críticas olham com desconfiança para conceitos como alienação, emancipação, libertação, autonomia, que supõem, todos, uma essência subjetiva que foi alterada e precisa ser restaurada". (SILVA, 2010, p. 140)

Os contextos em que estão sendo utilizadas tecnologias digitais no processo ensino e aprendizagem são propícios à reconstrução do currículo, de modo que se pode ter à disposição um web currículo o qual

[...]se desenvolve que a midiatização das ferramentas e interface das TDIC e se organiza em redes hipertextuais abertas ao estabelecimento de arcos que criam ligações entre nós, já estabelecidos, construídos por informações e também novos nós que integram conhecimentos previamente elaborados e conhecimentos em construção pelos novos aprendizes (estudantes, professores e outras pessoas) (ALMEIDA, 2014, in ALMEIDA et al, 2014, p. 28)

Desse modo, projetos, investigação científica, resolução de problemas, vivenciados por nós, ampliam as redes hipertextuais, usando diversas linguagens, estabelecendo uma interface entre componentes curriculares e culturas. Assim, um web currículo demanda sujeitos problematizadores, ativos - professor e estudante -, tecnologias digitais, culturas, proposta curricular e prática pedagógica de modo que se possa produzir conhecimento compartilhado e ter acesso a este.

Assim, a relação entre as tecnologias digitais e o currículo para se implantar um web currículo é complexa. Não se resume no uso de um computador em sala de aula, pois requerem investimentos cognitivos, sociais e culturais. Trata-se de uma oportunidade de se utilizar linguagens com fluência tecnológica para buscar e avaliar a qualidade de informações, propiciar redes dialógicas a fim de compartilhar produções, construir textos com recursos midiáticos, dar significado a pessoas de diferentes culturas, compreender o alcance de uma informação e a responsabilidade social por ela (ALMEIDA, in ALMEIDA et al, 2014)

Não é difícil reconhecer o quanto a escola ainda privilegia quase que exclusivamente a cultura dita "culta", sem levar em conta os multi e novos letramentos, as práticas, procedimentos e gêneros em circulação nos ambientes da cultura de massa e digital e no mundo hipermoderno atual. [...] As demandas sociais devem ser refletidas e refratadas criticamente nos/pelos currículos escolares [...] para que a escola 
possa qualificar a participação dos alunos nas práticas da web, na perspectiva da responsabilização, deve propiciar experiências significativas com produções de diferentes culturas e com práticas, procedimentos e gêneros que circulam em ambientes digitais: refletir sobre participações, avaliar a sustentação das opiniões, a pertinência e adequação de comentários, a imagem que se passa, a confiabilidade das fontes, apurar os critérios de curadoria e de seleção de textos/produções, refinar os processos de produção e recepção de textos multissemióticos. (ROJO e BARBOSA, 2015, p. 135)

Rojo (2013), nesse sentido, trata da pertinência de um design de um currículo pluralista no qual culturas e identidades dos estudantes precisam integrar a construção do conhecimento, considerando as possibilidades, conteúdos, grupos e contextos de aprendizagem. A diversidade cultural, identitária é positiva nesse cenário, propiciando a interatividade e a colaboração entre os aprendizes sobre etnia/raça, gêneros, diferenças em termos físicos e/ou cognitivos.

Vale ressaltar que web currículo, para cuidar das múltiplas linguagens e da diversidade de cultura, não se efetiva por meio da digitalização de conteúdos nem com o abandono de mídias tradicionais. Considera-se pertinente que o web currículo fomente a produção e recepção de conhecimentos, ressignificando-os “[...] por meio do diálogo intercultural, da mobilidade da informação, do ensino, da aprendizagem e do currículo, superando a fragmentação do conhecimento". (ALMEIDA, 2014, in ALMEIDA et al, 2014, p. 30). Assim, escola e mundo poderão, mutuamente, dialogar com mais facilidade.

Essa perspectiva extrapola o uso de dispositivos tecnológicos (transcende a ideia de usar o google search para tradução, o facebook para postagem de construções linguísticas que exemplifiquem figuras de linguagem e grupos no blog e facebook para postagem de resumos de leituras literárias), contempla fundamentos e finalidades educativas de um contexto peculiar a uma relação tempo-espaço favorável ao crescimento integral do professor e dos estudantes.

Para isso, é mister que o professor participe de um processo de formação na ação no qual possa explorar as TDIC em sua própria aprendizagem, identificar as contribuições dessas tecnologias ao ensino, à aprendizagem e ao currículo, utilizá-las em experiências com os seus alunos, refletir sobre essas práticas à luz de fundamentos teóricos e reconstruí-las. (ALMEIDA, 2014, in ALMEIDA et al, 2014, p. 31)

Ter como alicerce o web currículo faz parte de investirmos em uma prática de ensino transformada a partir de um fazer dinâmico e promotor de novos conhecimentos. (ALMEIDA, et al, 2014). Nesse sentido, educador e educando devem participar dialogicamente das práticas pedagógicas interativas de modo que aquele acompanha todo processo e incentiva a efetiva participação destes, tratando de conhecimentos universais e contextuais que se tornam significativos por meio da transposição didática. A colaboração, fortalecida pela interatividade, transversaliza esse evento pelo fato de os sujeitos que interagem nele buscarem o mesmo objetivo em uma atividade.

Essa dinâmica, por meio da aprendizagem móvel, transcende os referenciais físicos e geográficos e propicia o expressar de vozes nos tempos e espaços curriculares da escola e da cultura digital o que, a partir da efetividade de políticas públicas, requer ajustes na estrutura do contexto e na organização escolar, assim como a participação ativa de agentes, que se ousam a experimentar e dar sentido a novas experiências 
didáticas. O que está sendo problematizado não é o que a tecnologia digital faz conosco, mas, na condição de docentes de línguas, como vemos, representamos, atribuímos significados e usamos essas tecnologias tendo em vista a nossa preparação docente contínua e, por conseguinte, a formação crítica e ativa dos nossos educandos.

\section{Saberes e fazeres docentes em ambientes digitais no ensino e aprendizagem de línguas: limites e projeções}

A dissertação de mestrado de minha autoria, intitulada (Des) encontros entre as OCEM e o uso de blogs em práticas textuais no ensino e aprendizagem de línguas (SANTANA, 2013), aborda que pesquisadores, em função da utilização de tecnologias na educação, têm sido incentivados a estudar, não apenas, os novos usos da linguagem, mas também o impacto e as mudanças que estão ocorrendo no processo ensino e aprendizagem de línguas. Paiva (2012) nos lembra que o homem estabelece com a tecnologia digital uma relação dialética entre a adesão e a crítica ao novo.

O sistema educacional insere-se nesse processo, articulando-se a essa tecnologia, num movimento constituído pela rejeição, inserção e normalização. Paiva (2012) considera que, ao surgir um aparato tecnológico, são comuns a desconfiança e a rejeição. Aos poucos, a tecnologia começa a fazer parte das atividades sociais da linguagem, e a escola a incorpora em suas práticas pedagógicas. Em seguida, vivenciase o estágio da normalização, de modo que a tecnologia se integra naturalmente às práticas pedagógicas.

Nesse processo de impacto e mudança, de rejeição e adesão à tecnologia, em particular no ensino de línguas, como converter tecnologias da informação e da comunicação em tecnologias da aprendizagem no ensino e aprendizagem de línguas? Este é um questionamento suscitado pela leitura do texto Das TIC às TAC da autora Juana Sancho (2008). Dessa leitura, depreende-se que, para isso, é essencial o investimento na formação continuada do professor de modo que não haja apenas a integração dessas tecnologias em sala de aula, mas recursos para inclusão digital e um agente que inova a ação educativa.

Essa perspectiva transcende uma prática centrada num ensino formal da língua, bem como na ação do professor (o que tem sido elementar como proposta de muitas formações iniciais do docente), levando em conta as culturas existentes, as práticas estabelecidas, as relações de poder, as concepções sobre ensino e aprendizagem entre outros aspectos (SANCHO, 2008).

É comum estudantes avaliarem que o resultado do trabalho com as tecnologias da aprendizagem e da comunicação os motiva para o estudo tanto individual como coletivo, considerando as necessidades peculiares do grupo com o qual se articula nesse processo. A par disso, é muito importante investir na autoria e na autonomia dos estudantes, construir comunidades virtuais entre escolas, fortalecer as equipes colaborativas de docentes, dividir e ampliar conhecimentos construídos, fomentar os questionamentos a partir de propostas de resolução de problemas, incrementar as habilidades de aprender a aprender a partir de inovações, a exemplo quando se fala em aprendizagem móvel, e ter um apoio da equipe escolar no empreendimento das atividades pedagógicas.

Nas palavras de Aragão,

Para que mudanças efetivas venham a ser consolidadas no ensino de Línguas [...] um dos caminhos é investir em pesquisa sobre o ensino/aprendizagem na rede regular, na formação do professor e na 
utilização produtiva e efetiva de tecnologias educacionais, tanto as tradicionais quanto as novas tecnologias da informação e da comunicação. (ARAGÃO, 2009, p. 59)

Kleiman (2001) entende ser relevante investir na formação linguística do professor e defende o desenvolvimento do letramento do professor para e no local de trabalho. Destaca a necessidade de se contemplar uma formação linguística mais aprofundada para a docência de modo que haja uma transposição interdiscursiva entre os saberes linguísticos e os saberes didáticos (ROJO, 2011).

Isso requer ação no contexto das novas tecnologias, aquisição de performance didática e currículo diferenciado, ativez da criticidade e da participação política decorrente de outras formas de interagir com as linguagens, com o conhecimento, assim como com uma formação para organizar ambiências pedagógicas que potencializem a vivência dos multiletramentos.

As abordagens de Santos (2005) dialogam com essas considerações. Para a autora, o professor precisa

[...] arquitetar ambiências formativas, inteligentes e desafiadoras, que preparem as pessoas para o exercício da cidadania, ou seja, para afetar a cidade e se apropriar dos seus equipamentos e paisagens de forma cidadã. Isso não acontece sem processos formativos educacionais, sem investimento público e privado e sem a integração de redes educativas diversas. Por outro lado, ele não pode criar essas ambiências se não as vivenciar, se não ampliar o seu próprio repertório. Por isso, o professor é um profissional que se educa o tempo todo em relação ao ciberespaço. Ele também não pode abrir mão do processo de mediação, que é estar junto aos alunos. Não apenas criar ambiência, mas a presença física, simbólica e comunicacional faz com que esses espaços sejam melhores aproveitados. (SANTOS, 2005, p. 01)

Santos (2005) adverte que a performance docente nesse processo não é simples, em especial, por conta de limitações na infraestrutura (que envolve a pequena disponibilidade de artefatos tecnológicos e a escassa potencialidade de wifi), nas condições de trabalho e na formação docente. A mediação pedagógica requer do professor saberes e fazeres atualizados e

[...]passa pela arquitetura das ambiências formativas, mas também de estar ao lado dos alunos na caminhada de transformar dado em formação, formação em conhecimento que seja contextualizado, que consiga refletir sobre problemas cotidianos sem perder de vista o mundo globalizado, onde os problemas dos outros também são nossos. A mediação é feita sobre a linguagem, que se materializa em diversos dispositivos. Um filme, uma leitura, um gênero, uma exposição fotográfica, tudo isso afeta. Se temos um professor bem formado e com repertório ampliado, respeitoso, e que considera também o aluno como rede mediadora, teremos uma educação. (SANTOS, 2005, p. 01)

Isso implica investimento na educação linguística ${ }^{3}$ multiletrada (AZZARI; LOPES 2013, in ROJO, 2013) no sentido de se empreender o ensino e aprendizagem de

\footnotetext{
${ }^{3}$ O conceito de Educação Linguística, utilizando inicialmente no Brasil por Bechara (2000), parte da premissa de que o ensino de línguas não pode ser confundido com o estudo da gramática, visto que
} 
línguas materna ou estrangeira por meio de atividades sistematicamente organizadas em sequências didáticas "[...]para atuação e performance (projetos colaborativos, protagonistas): um currículo em que, ativamente, se produzem e se criam significados sociais",

Acreditando que uma boa educação linguística deva exercer seu papel de fornecer as competências e conhecimentos de que os alunos necessitam para atuar na contemporaneidade, procuramos trabalhar a leitura e a produção textual sob a perspectiva dos multiletramentos. Acreditamos em uma concepção de letramento que seja "um conjunto de competências culturais para construir significados sociais reconhecíveis através do uso de tecnologias materiais particulares “ (LEMKE, 2010, p 02). De acordo com Lankshear e Knobel (2011), os letramentos multimodais e multissemióticos, intrínsecos a tecnologias digitais, apresentam um novo ethos que os distinguem, de forma marcante, do conceito convencional de letramento. Dessa forma, uma educação linguística que dê conta dos novos letramentos implica uma "reconfiguração de valores" em relação a uma pedagogia convencional (LANKSHEAR e KNOBEL, 2011, p. 72), a fim de atender às necessidades do alunado pertencente à sociedade contemporânea, na qual a informação se propaga de forma rápida e interativa. (AZZARI; LOPES, 2013, in ROJO, 2013, p. 194 e 195)

Rojo e Barbosa (2015) tratam, como um protótipo ${ }^{4}$, de algumas situações práticas por meio das quais se pode empreender um referencial de web currículo necessário à efetividade de uma educação linguística, quando, por exemplo, na aula de literatura é possível usar as fanfics, prática em que se elege como fã um personagem de um romance de literatura, quadrinhos, série etc e faz-se registros em ambientes digitais, como blogs, revelando o porquê da eleição. As fanfics comumente são metalinguísticas, pois seu produtor, ao elaborá-las, pensa sobre o uso contextual da língua, adequando o texto ao propósito comunicativo da produção, bem como aos comentários que recebem a cada capítulo publicado, lançando mão, para tanto, da colaboração. No que se refere às práticas com os textos literários, as fanfics oportunizam o trabalho com a literatura valorizada pela cultura juvenil, considerando que os estudantes podem partir de um design sugerido pela obra literária para um redesenho que entenderem como pertinente. (AZZARI e CUSTÓDIO, 2013, in ROJO, 2013)

É possível também criar narrativas transmídias ou híbridas nesses ambientes, fazendo paródias de livros, filmes de modo que se valorizem a cultura literária e a tradição, podendo, na condição de leitor empírico, lançar outros olhares para a narrativa. Esse tipo de produção pode ou não partir de outras existentes. Caso haja o intertexto, haverá o que se chama de remixagem, exemplificada pelos memes (adaptações em vídeo, imagem, frase ou, até mesmo, pelas hashtags, para veicular rapidamente um dado sentido; atualmente, são utilizados como paródias), AMV (animes em que se combinam o ritmo de cenas com os de músicas), mashup (canção ou composição proveniente da integração de duas ou mais outras canções geralmente pela transposição do vocal de uma canção em cima do instrumental de outra, de forma a se combinarem), entre outros.

integra o desenvolvimento das potencialidades comunicativas do educando em termos linguísticos, textuais, sociodiscursivo o que também é peculiar ao ensino e aprendizagem de línguas em ambientes digitais.

${ }^{4}$ Protótipo (ROJO, 2015) referem-se às SD que têm propostas de ensino flexíveis e vazadas como um potencial para o professor, com autonomia, empreender os arranjos pedagógicos. 
Outras experiências sugestivas para o docente criar um repertório relevante ao empreendimento do ensino e aprendizagem de línguas por meio de tecnologias digitais referem-se ao fanclipe, fanzine, e-zine, videominuto, playlist comentada, enciclopédia colaborativa, revista digital. Todos eles requerem o conhecimento computacional (com o domínio de edição de fotos, áudio e vídeo), bem como o uso prudente de tecnologias digitais.

O trabalho com essas propostas fomenta o "seguir" alguém, alguma publicação e, assim, num processo interativo e de colaboração, acionam-se o

[...]curtir, comentar, redistribuir (sem comentar), redistribuir com comentário fundamentado (redistribuição crítica) etc. -; outras não tão diretamente acessíveis: publicações em outras redes ou espaços sem referências diretas às origens. Essas publicações/respostas também podem ser multimodais: podem misturar diferentes linguagens (para além da verbal, vídeos, áudios, imagens de diferentes tipos, estáticas ou em movimento etc). (ROJO; BARBOSA, 2015, p. 123)

A BNCC (2018) recupera essas sugestões e traz indicativos de outras, apresentando, por exemplo, algumas habilidades que precisam ser cultivadas nesse repertório, referentes à competência específica 07, a saber: mobilizar práticas de linguagem no universo digital, considerando as dimensões técnicas, críticas, criativas, éticas e estéticas, para expandir as formas de produzir sentidos, de engajar-se em práticas autorais e coletivas, e de aprender a aprender nos campos da ciência, cultura, trabalho, informação e vida pessoal e coletiva.

O investimento na exequibilidade dessa competência, em especial, propiciará aos jovens uma visão crítica, ética e estética, transcendendo o uso técnico das tecnologias da informação e da comunicação (referente às linguagens de programação, ferramentas e apps variados de edição de áudio, vídeo, imagens, criação de games, memes, entre outros) a fim de que se possa selecionar, filtrar, compreender e produzir criticamente sentidos em quaisquer campos da vida social. habilidades:

Para tanto, a BNCC (2018, p. 489) propõe a efetividade das seguintes

(EM13LGG701) Explorar tecnologias digitais da informação e comunicação (TDIC), compreendendo seus princípios e funcionalidades, e mobilizá-las de modo ético, responsável e adequado a práticas de linguagem em diferentes contextos.

(EM13LGG702) Avaliar o impacto das tecnologias digitais da informação e comunicação (TDIC) na formação do sujeito e em suas práticas sociais, para fazer uso crítico dessa mídia em práticas de seleção, compreensão e produção de discursos em ambiente digital.

(EM13LGG703) Utilizar diferentes linguagens, mídias e ferramentas digitais em processos de produção coletiva, colaborativa e projetos autorais em ambientes digitais.

(EM13LGG704) Apropriar-se criticamente de processos de pesquisa e busca de informação, por meio de ferramentas e dos novos formatos de produção e distribuição do conhecimento na cultura de rede.

Propostas pedagógicas utilizadas para viabilizar a efetividade dessas habilidades concernentes à competência específica 07 (BNCC, 2018) devem considerar a aprendizagem da leitura e da escrita como outra oportunidade de significar, fazer sentido e circular na sociedade contemporânea (COPE; KALANTZIS, 2008). O design digital e as hipermídias são novas linguagens que produzem pensares heterogêneos, 
convergentes e não-lineares importantes à formação das pessoas e de sua ambiência (SANTAELLA, 2008). O aprendiz, nesse sentido, é o protagonista do processo de transformação e produção do conhecimento e não um mero reprodutor de saberes. Os professores também precisam atuar como produtores de conhecimento por meio do contato interativo com os dispositivos digitais, num processo dialógico e colaborativo com os estudantes.

\section{Sobre algumas conquistas da pesquisa-formação: entre a autoetnografia, a etnografia, aquela inferface necessária com os multiletramentos.}

Considerando as interações com registros autoetnográficos e etnográficos sobre os nossos convívios com tecnologias, o processo formacional para o ensino de línguas em ambientes digitais e as experiências desse ensino em um contexto escolar, vemos que são grandes os desafios e satisfatórias as conquistas de um investimento qualitativo na pesquisa-formação quando se entende o quão potencial é a profissionalidade docente.

A pesquisa que ilustra essa consideração envolve práticas docentes e processos formacionais que fortalecem a identidade profissional. Há incipiências, vontades, conquistas que nos permitem uma maior familiaridade e propor caminhos para se vivenciar práticas do ensino e aprendizagem de línguas.

Segundo Perrenoud (2000), o uso de tecnologias nas atividades educacionais implica na utilização de editores de textos, na exploração das potencialidades didáticas de programas em relação aos objetivos de ensino, na comunicação à distância por meio da telemática e na utilização de ferramentas multimídia no ensino. Essa abordagem dialoga bem com a referência de tecnologia como artefato, produção (CUPANI, 2016; FOUCAULT, 1995), o que se resume em técnica, bem peculiar a algumas interações tecnológicas mediadas por mim, LP e LI no contexto escolar.

Para ilustrar essa questão, mais precisamente, tendo em vista alguns recortes da pesquisa, eu propus aos educandos que postassem resumos de livros em blogs, com fins na avaliação da leitura literária. LP, a propósito, solicitou que registrassem no facebook exemplos de palavras próprias do léxico referente à ementa de um curso profissional ofertado no CETEP do Baixo Sul, e LI recorreu, consideravelmente, ao uso do google search para tradução e treino de pronúncias na língua inglesa (conforme referenciais do questionário e da entrevista aplicados em julho e agosto de 2016 para os sujeitos da pesquisa no CETEP do Baixo Sul). As nossas limitações poderão também ser reflexos de cursos que não fizemos ou da incipiência peculiar a algumas propostas de formação docente no que se refere ao trabalho com tecnologias digitais no que-fazer educacional. Há também um forte vínculo com o currículo tradicional.

Essa abordagem me remete a traços de minhas atividades didáticas, bem como das de LP e de LI, ilustrados nas passagens abaixo que foram registradas na transcrição da entrevista realizada em agosto de 2016. Essas falas consistiram em respostas para as perguntas sobre as atividades que propomos e que requerem o uso de tecnologias digitais:

LI: Proponho o trabalho com o monólogo: eu dou um tema Gravidez na adolescência, peço para escrever cinco linhas, os alunos vão ao google tradutor, traduzir para o inglês, no próprio google aprendem a pronúncia, ensaio com eles, na apresentação quando aparece a tradução ao pé da letra, vou reparando: "o google tradutor falou isso, mas se pronuncia assim[...]" (Entrevista, agosto de 2016) 
LP: Quando eu trabalhei formação de palavras, prefixo e sufixo sobre a área de formação, pedi aos alunos para postarem no Face [...] (Entrevista, agosto de 2016)

Recorte Autoetnógrafico: Proponho pesquisa de artigos, textos outros, cuja leitura ajudem na argumentação de dissertações; registros em blogs e grupos de face referentes à leitura de textos literários; publicação de propagandas construídas pelos grupos acerca desses livros; pesquisa complementares referentes aos aspectos linguísticos; webquests. (Entrevista, agosto de 2016).

Vê-se nessas falas que o "o quê" ocupou um espaço significativo em nossas ações pedagógicas. Quando LI reiteradamente solicitou que os alunos traduzissem textos e praticassem a pronúncia por meio do "google search", LP propôs que os educandos postassem exemplos de palavras, com determinadas estruturas, no facebook, e eu pedia aos educandos que publicassem resumos de livros literários em blogs e grupos no facebook, vejo os reflexos de um currículo baseado em teorias tradicionais (SILVA, 2010).

O nosso investimento pedagógico, nesse sentido, tinha com fim o "o quê" trabalhar, a efetividade de uma metodologia, de um processo avaliativo que incidia na classificação. Em alguns momentos, de posse de uma certa autonomia, já propúnhamos (conforme registros constantes na entrevista aplicada aos sujeitos em agosto de 2016) estudos sobre temas voltados para os direitos e deveres humanos, o que é peculiar à perspectiva crítica e pós-crítica de currículo, instaurando um entrelugar para os multiletramentos, a exemplo da mediação de leituras, escritas e falas, em inglês, sobre o respeito aos idosos - LI; investimento na racionalização da água com orientações de pesquisa em sites para discussão e produção de um artigo de opinião - LP - e um olhar mais crítico para as articulações entre os portugueses aqui no Brasil, no século $\mathrm{XV}$, por meio do estudo da Carta de Pero Vaz de Caminha com registros no facebook - LP), passando-se, portanto, a contemplar, oportunamente, questões referentes ao saber, poder e identidade.

Almeida (2014, in ALMEIDA et al, 2014) salienta que a prática pedagógica com tecnologias digitais, por um lado, pode ter como alicerce um currículo prescritivo centrado em conteúdos determinados, métodos instrucionais baseados na disseminação de informações, materiais didáticos digitalizados, no uso do software para repetição do padrão disciplinar, na avaliação somativa e excludente. Por outro lado, pode contar com uma proposta de currículo reconstruído que favorece a expressão de ideias, a interação social, a navegação não linear, usando o hipertexto, a exploração, seleção e articulação crítica de informações dispostas em diversas linguagens, a participação em rede de conexões horizontais, a colaboração entre as pessoas por meio de processos interativos síncronos e assíncronos.

A abordagem de currículo reconstruído privilegia

[...] a experiência, a formação para a cidadania responsável de sujeitos críticos e criativos, conscientes das possibilidades de acesso e uso dos instrumentos culturais de seu tempo para enfrentar as problemáticas da vida com a ética inerente ao desenvolvimento da vida digna, plena de oportunidades para sua formação profissional, cultural, social e pessoa. (ALMEIDA et al, 2014, p. 26)

Para ativar um trabalho pedagógico que integre o currículo escolar, num viés pós-crítico, e o uso de tecnologias digitais, avalio como oportuno o entendimento e a 
efetividade do web currículo no processo ensino e aprendizagem de línguas. Almeida (2014) referencia web currículo como

[...]o currículo que se desenvolve por meio das tecnologias digitais de informação e comunicação, especialmente mediado pela internet. Uma forma de trabalhá-lo é informatizar o ensino ao colocar o material didático na rede. Mas o web currículo vai além disso: ele implica a incorporação das principais características desse meio digital no desenvolvimento do currículo. Isto é, implica apropriar-se dessas tecnologias em prol da interação, do trabalho colaborativo e do protagonismo entre todas as pessoas para o desenvolvimento do currículo. É uma integração entre o que está no documento prescrito e previsto com uma intencionalidade de propiciar o aprendizado de conhecimentos científicos com base naquilo que o estudante já traz de sua experiência. O web currículo está a favor do projeto pedagógico. Não se trata mais do uso eventual da tecnologia, mas de uma forma integrada com as atividades em sala de aula. (ALMEIDA, 2014, in ALMEIDA et al, 2014, p. 29)

A partir do que a vivência na cultura digital impele, dos reflexos da formação continuada, autônoma ou oferecida por órgãos públicos, bem como da pesquisaformação e da vivência do webcurrículo, eu, LP e LI já demonstramos traços da realização de algumas dessas atividades práticas. LI intermediou uma sequência didática para a produção de uma foto-história no celular, com edição de fotos e legendas em inglês, sobre o respeito às diferenças no convívio interpessoal; LP orientou um trabalho didático no whatsapp para o estudo do Barroco, por meio do qual, o estudante protagonizou a produção do conhecimento sobre essa estética literária num sentido atemporal e glocal, usando o hipertexto, a multimodalidade e a colaboração. Eu, como reflexo de um amadurecimento profissional (transcendendo a compreensão do espaço blog e facebook para a postagem de resumos literários como crédito de avaliação da aprendizagem), sugeri que os estudantes produzissem memes relacionados à intolerância religiosa, bem como étnica e racial, a partir do estudo da obra Tenda dos Milagres de Jorge Amado.

Nessas experiências, os estudantes usaram funcionalmente o conhecimento computacional, criaram sentidos, fizeram análise crítica do conteúdo das produções e transformaram conhecimentos na perspectiva do produtor e do leitor/ouvinte/expectador, o que é peculiar à proposta dos multiletramentos tratada por Rojo e Barbosa (2015) e o que me dá sustentações teóricas e práticas para exemplificar a possibilidade de se vivenciar a os multiletramentos no ensino e aprendizagem de línguas em ambientes digitais.

Nóvoa (1997) contribui consideravelmente para se pensar uma proposta de formação que amplie, aprimore as formações inicias para os docentes que lidam com o ensino e aprendizagem de línguas, bem como aquelas ofertadas por órgãos governamentais, a exemplo do Curso de Atualização em Tecnologias Educacionais $\mathrm{CATE}^{5}$, pois, ainda que se intencione oferecer ao docente aprimoramentos conceituais e práticos acerca do trabalho com tecnologias digitais, falta espaço para o profissional ecoar a sua voz, considerando suas dúvidas, limitações, conquistas a partir do contexto glocal no qual atua e das interações que estabelece com os sujeitos aprendizes num viés da pesquisa-formação. LI não terminou o curso, salientando que não via perspectivas de

\footnotetext{
${ }^{5}$ Curso de Atualização em Tecnologias Educacionais oferecido pela Rede Estadual de Ensino da Bahia, no AVATE (Ambiente Virtual de Aprendizagem) entre 2014 e 2015, para os docentes.
} 
aplicabilidade prática da proposta de formação de modo que preferia ser autodidata também para o trabalho com as tecnologias digitais nas aulas de língua inglesa, visto que, até mesmo, a universidade não o preparou para dar aulas.

$\mathrm{Eu}$ e LP ampliamos nossos conhecimentos sobre tecnologias, acerca de possibilidades de trabalho pedagógico com conteúdos digitais, ao vivenciarmos as atividades do CATE no Ambiente Virtual de Aprendizagem - AVATE, embora ainda ficássemos apegadas ao entendimento e empreendimento da tecnologia como um suporte para a aprendizagem do sistema da língua escrita. Colegas liam nossos registros em fóruns, mas não tínhamos um feedback no sentido de não se restringir a um uso de uma outra técnica em nossas ações didáticas. Devolutivas, num movimento da reflexãoação-reflexão, permitem que os professores se apropriem dos seus processos de formação de modo que possam dar maior sentido a eles.

Alguns registros da entrevista ${ }^{6}$ aplicada em agosto de 2016 - quando questionados sobre se a nossa formação inicial e continuada contemplou orientações para o trabalho pedagógico com tecnologias digitais - elucidam essa abordagem nos dois excertos que seguem em que LI, LP e eu falamos sobre nossos processos formativos:

LI: [...] na universidade, as aulas de inglês aconteciam de forma tradicional, o professor e o módulo na universidade não me ensinaram a ensinar inglês, o professor teve que parar para ensinar inglês, eu precisava de método, nenhum momento me ensinaram como ensinar inglês, muito menos usar tecnologias nas aulas de inglês [...] eu acho o ensino acadêmico, muito acadêmico, o curso de licenciatura é muito acadêmico não ensina a ensinar o que os teóricos acham, além da reforma do EM é preciso haver reforma nos cursos de licenciatura que ensinem a ensinar. Ah sim...Não gostei do CATE [...] achei meio utópico, me inscrevi, comecei, aquele curso não ensina como deve fazer [...] onde está a lousa eletrônica, onde está o wifi, onde está o data show, desmotivei eu vou estudar e usar como [...] é porque ali está dizendo em bom português essa tecnologia é essa, você fica sabendo como usa e vai usar como (isso me afastou) você excita, você provoca, mas você puxa o tapete. [...] Eu sou aquariano, sou objetivo não gosto de perder tempo, não tem o cabo data show, eu acho que é, o curso vou fazer para aumentar o salário, eu não faço nada para aumentar o salário se aquilo não significar nada para mim se aquilo não for real [...] não gosto de mentira. Eu vou mentir para você e você vai ouvir e ganhar bem [...] Muito bom, mas eu não usaria. Ficaria mais angustiado, sei usar mas não tenho como usar. [...] Eu sou autodidata (o que motivou usar o google search) eu vou vendo o que meu aluno precisa eu me coloco no lugar do aluno eu fui descobrindo

\footnotetext{
${ }^{6}$ Utilizarei como norma de transcrição da entrevista (gravada em áudio em agosto de 2016), algumas orientações do Projeto NURC (Norma Urbana Culta) disponíveis no site: http://www.concordancia.letras.ufrj.br, acesso em abril de 2017. A transcrição não é fonética, segue-se a ortografia da língua padrão; para indicar truncamento, interrupção discursiva, usa-se o /; as reticências ... indicam pausa e os parênteses ( ) incompreensão de palavras ou de segmentos; faço o registro dos fáticos (né) e de expressões reduzidas próprias do uso informal da língua (cê). Sigo também orientações da ABNT - Associação Brasileira de Normas Técnicas (2002), considerando a fala do participante como a de um autor que, ao invés de apresentar um texto escrito, apresenta um documento falado. Assim, grande parte das citações com mais de três linhas são registradas com um recuo de $4 \mathrm{~cm}$ e em letra com corpo menor; 4) as supressões, no início ou no meio do texto, são apresentadas com a indicação de reticências entre parênteses.
} 
sozinho como usar o google... acho mais interessante quando você não ganha dinheiro para fazer as coisas (o colega fazia para o outro) [...] $\mathrm{O}$ curso era muito bom... Eu lembro de uma aula ensinava você a escolher vídeos na internet que tivesse ou não direitos autorais (não cair na coisa dos direitos autorais) agora eu prefiro eu mesmo descobrir, eu não sei o que acontece comigo, eu prefiro eu mesmo descobrir, eu não tenho nada contra o curso a maneira como foi feito não me motivou.[...]Meu grande sonho é o aluno ser protagonista, quem quer aprender inglês não precisa de escola. [...] Meu grande sonho é que essas tecnologias fiquem disponíveis na sala, eu acho cruel você colocar o menino na sala de sala e a sala de aula não parece a vida real o aluno vem para o século XIX no século XXI. A escola precisa entrar no século XXI, e a tecnologia vai ajudar (não é a única forma) não podemos afastar a vida real da sala de aula. (Entrevista, Agosto de 2016).

LP: Um curso específico não, fiz um minicurso multimídias na educação naquela época como usar transparência retroprojetor... foi uma sementinha...eu nem sonhava em ter um celular, foi um curso de 4 horas, 02 horas em cada dia, com apostila e explicação sobre. [...]O CATE, o curso contribuiu sim, na minha opinião precisa ser semipresencial, por exemplo duas atividades no AVA e uma que retomasse tudo e até mesmo a gente praticasse alguma coisa eu tive que aprender pela necessidade (não somos nativos digitais) eu tenho colegas que não sabem usar pendrive... Estudamos deficiência, currículo, memória, subjetividade, o portal Anísio Teixeira a nossa disposição, um acervo riquíssimo, nesse caminho conhecendo as mídias [...] Antes do curso usava 20\% de tecnologias em minhas aulas, depois $40 \%$ e se tivesse outra estrutura $60 \%$, eu trabalho 60 horas e preciso de tempo para lincar as coisas, você vai trabalhar a música como apresentar, o que discutir, para a música não ser pretexto. [...] Eu mudei a minha postura, eu visito o portal do educador, às vezes, vou lá pego algo [...] tinha algo no curso muito da teoria $[\ldots] \mathrm{O}$ tablete (o meu tablet não consegui configurar, muitos professores devolveram, é preciso investimento em política pública de inclusão, não só formação teórica, eu penso que se essa formação fosse dividida teórico e prática, TV pen drive arquivo de museu. (Entrevista, agosto de 2016)

Recorte Autoetnográfico: $\mathrm{Na}$ faculdade, minha experiência com computador, no laboratório de informática da UNEB foi em 2000. Fiz curso de mídias na educação em nível de extensão e de pós-graduação, aprendi a participar de fóruns, do AVA, a preparar jogos no JPEG. O CATE me permitiu aprimorar práticas de ensino por meio de tecnologias de modo a tornar esse ensino mais crítico. (Entrevista, agosto de 2016)

LI sinalizou as limitações do processo formativo no contexto da licenciatura que se distancia do "saber/fazer". Revela ser autônomo quanto à busca de sugestões de ações que também contemplem o trabalho com tecnologias. É também prudente quando diz que não participa de formações, tendo em vista, tão somente, a promoção salarial, pois tem um compromisso com a efetividade do protagonismo do educando.

LP, por usa vez, mostrou-se empenhada, a partir de investimentos de formação para implementar as práticas de sala de aula por meio dos ambientes digitais. Porém, recomendou que outros cursos, com a intenção de orientar a atividade docente, 
apresentem mais possibilidades de trabalhos práticos referentes ao ensino de línguas. Tal como LI, LP associa o trabalho com tecnologias digitais à técnica por fazer referência a alguns recursos ausentes no contexto escolar e dar destaque ao conhecimento para o uso do pendrive, da TV pendrive do Tablet Educacional.

Eu tive oportunidade de participar de cursos que promovessem a aprendizagem para o uso do recurso digital no ambiente educacional, mas ainda com apego ao conhecimento e utilização da técnica como artefato no contexto do problema da pesquisa.

Diante disso, considerei importante no processo da autoetnografia e da etnografia, lançar mão da pesquisa-formação para que os resultados da ação docente fossem nosso objeto de análise de modo que pudéssemos redimensionar saberes e fazeres. Assim,

O triplo movimento sugerido por Schon (1990) - conhecimento na ação, reflexão na ação e reflexão sobre a ação e sobre a reflexão na ação - ganha uma pertinência acrescida no quadro do desenvolvimento pessoal dos professores e remete para a consolidação no terreno profissional de espaços de (auto)formação participada. Os momentos de balanço retrospectivo sobre os percursos pessoais e profissionais são momentos em que cada um produz a "sua" vida, o que no caso dos professores é também produzir a "sua" profissão. (NÓVOA, 1997, p. 26)

Mais precisamente, vê-se que práticas de formação continuada organizadas em torno dos professores individuais, assim como coletivas em ambientes digitais, sem uma devolutiva e a retroalimentação da ação, podem até ser válidas para a aquisição de conhecimentos e de técnicas, contudo fomentam o isolamento, reforçando uma imagem dos professores como transmissores de um saber produzido no exterior da profissão. Por outro lado, práticas de formação que se referenciam nas dimensões coletivas favorecem emancipação profissional para a consolidação de uma profissão autônoma na produção dos seus saberes e dos seus valores.

A pesquisa-formação (ANDRÉ, 2002; BUENO, 2000; RAUSCH, 2012) coaduna com essa perspectiva, pois quando me reuni com LP e LI para o estudo dos documentos curriculares, em encontros para dialogarmos sobre nossas práticas em ambientes digitais e analisarmos outras experiências nesse sentido, a intenção não era termos uma receita, mas alimentarmos as forças e as oportunidades pedagógicas as quais tanto nos afirmassem em nossa função, de modo que orientássemos os educandos a interagirem por meio das mídias e atuarem na cultura participativa que emerge constantemente.

A formação pode estimular o desenvolvimento profissional dos professores, no quadro de uma autonomia contextualizada da profissão docente. Importa valorizar paradigmas de formação promotores da preparação de professores reflexivos, que assumam a responsabilidade do seu próprio desenvolvimento profissional e que participem como protagonistas na implementação das políticas educativas. É preciso investir positivamente nos saberes de que o professor é portador, trabalhando-os de um ponto de vista teórico e conceitual. Os problemas da prática profissional docente não são meramente instrumentais; todos eles comportam situações problemáticas que obrigam a decisões num terreno de grande complexidade, incerteza, singularidade e de conflito de valores (SCHON, 1992). A formação contempla a experimentação, inovação, ensaio de novos modos de trabalho pedagógico a partir da reflexão crítica e de processos de investigação diretamente articulados com as práticas educativas. 
Sabemos que a formação do professor se dá durante a ação pedagógica e não é a única responsável pela transformação educacional. Entendo formação, assim como Nóvoa (1997), em termos ecológicos que contemplam tanto o professor, como os contextos escolares o que demanda um investimento educativo nos projetos da escola enquanto um ambiente educativo, onde trabalhar e formar sejam indissociáveis. Há, portanto, a necessidade de articular a formação contínua com a gestão escolar, as práticas curriculares e as necessidades dos professores numa perspectiva sistêmica.

É producente que a formação contínua potencialize as experiências inovadoras e as redes de trabalho existentes no sistema educativo, investindo-as do ponto de vista da sua transformação qualitativa, em vez de instaurar novos dispositivos de controle e de enquadramento. A formação se dá por meio da mudança dos professores e das escolas, o que não se torna inviável sem um investimento positivo nas experiências inovadoras. Se assim não for, desencadeiam-se fenômenos de resistência pessoal e institucional promovendo a passividade de muitos atores educativos.

Em análise de nossos saberes e fazeres sobre a vivência dos multiletramentos no ensino e aprendizagem de línguas, é interessante destacar que tanto em nossa formação inicial, bem como na continuada (por meio de alguns cursos e de especialização) e, até mesmo, em algumas ações autônomas autorizadas pelo próprio processo de formação, temos algumas limitações, manifestamos resistências e vamos compreendendo melhor como utilizar tecnologias digitais a partir do que impele a vivência na sociedade tecnológica digital. Para tanto, é necessário conhecimento técnico (o que estamos aprimorando), compromisso com o que é atrativo e significativo para a aprendizagem dos educandos ser mais significativa, sempre reiterando o valor de nossa performance profissional.

A partir dos traços de uma educação tradicional, baseada em saberes consagrados, que tivemos em nossa formação como educandos e, até mesmo inicialmente, como profissionais (em entrevista, LI disse que a universidade ensina tudo, menos a dar aula), é preciso muito investimento em formação docente, tanto pessoal como por parte de políticas públicas, bem como em redimensionamento de propostas curriculares para mediarmos um ensino de línguas que, de fato, assegure a todos a vivência dos multiletramentos, também por meio do uso de tecnologias digitais.

A necessidade de investimentos na formação docente, dada as inquietudes que os cenários educacionais oferecem, encontra-se na agenda da Linguística Aplicada. Esta tem um papel relevante já que lhe convém trazer à tona novos esquemas de politização para o ensino de línguas em geral.

\section{Considerações Finais}

A discussão empreendida neste artigo elucida que a formação do professor interfere na vivência de multiletramentos no ensino e aprendizagem de línguas em ambientes digitais. Entender e efetivar o ensino e aprendizagem de línguas nessa perspectiva nos faz compreender que a ação pedagógica transcende o ofício e a missão da docência por se entender que as interações educativas no contexto atual implicam no investimento na profissionalidade.

Nessa lógica, acredito que o uso das tecnologias digitais torna-se consequência de uma mudança de postura dos professores que passam a compreender o potencial tecnológico para a construção de ricos ambientes de aprendizagem. Ressalta-se que o investimento em um web currículo será oportuno nesse processo. 
Mesmo diante de algumas adversidades - sinalizadas por mim, LI e LP, como o apego ao ensino de línguas na perspectiva da cultura da língua escrita, restrições na infraestrutura da escola, a não equidade de acesso a tecnologias digitais para todos os educandos, necessidades de mais investimento autônomo e por parte de políticas públicas na formação docente -, nesse cenário, compreendo que a profissionalidade docente, construída progressivamente no contínuo do exercício da docência, diante da emergência de se efetivar o web currículo cujo cerne seja, multiletramentos no ensino e aprendizagem de línguas em ambientes digitais, implica:

- interagir por meio da língua e não estudar sobremaneira sobre a língua, entendendo-a como um polissistema que integra as dimensões histórica, social, cultural e formal o que contempla o trabalho com as dimensões para a produção e recepção dos sentidos do texto (BRASIL, 2006).

- vivenciar multiletramentos, com um contato informacional, crítico, criativo e estético, com as múltiplas linguagens e a multiplicidade da cultura glocal o que envolve práticas educacionais no universo multissemiótico, com a multimodalidade e o hipertexto, a interatividade, colaboração, interculturalidade e transculturalidade.

- engajar-se no uso de tecnologias digitais o que não se limita à utilização de artefatos, mas de um pensar e de um agir tecnológicos. A experiência da tecnologia é algo que nos inclui e nos modifica. A BNCC (2018) propõe o investimento no conhecimento da computação e programação (utilização de ferramentas digitais, produção multimídia e uso da linguagem de programação); do pensamento computacional (domínio de algoritmos, visualização e análise de dados) e da cultura e mundo digital (compreensão do impacto das tecnologias na vida das pessoas e na sociedade, incluindo nas relações sociais, culturais e comerciais e a utilização ética dessas tecnologias).

Falar desse lugar é um exercício intelectual e político necessário. Na condição de docente-pesquisadora, destaco meu anseio em fortalecer minha inscrição nesse processo, pois o que se coloca em tese não é, necessariamente, a descrição de um ensino e aprendizagem de línguas por meio de artefatos tecnológicos, mas como é possível mobilizar pensamentos, ações, formações, autoformações docentes no sentido de viabilizar e/ou fortalecer o instaurar os multiletramentos em eventos escolares situados. Nesse sentido, a técnica aqui transcende à referência de instrumental para mobilizar um saber e um fazer docente.

Para mediá-lo com proatividade, a participação em formações continuadas é essencial e contínua enquanto alimento da profissionalidade. Saberes e fazeres concernentes ao ensino e aprendizagem de línguas precisam ser aperfeiçoados sempre. Na pesquisa-formação, isso se evidenciou por meio da etnografia e da autoetnografia, cujas vozes e vezes dos sujeitos revelaram possibilidades de ações pedagógicas na perspectiva dos multiletramentos. Então, é oportuno se ativar as interações por meio de ambientes digitais para assegurar a aprendizagem significativa e contextualizada de línguas tendo como alicerce o web currículo.

\section{Referências}

ALMEIDA, et al. Web currículo (recurso eletrônico). Aprendizagem, recurso e conhecimento com o uso de tecnologias digitais. Rio de Janeiro: Letra Capital, 2014, p. 30 e 31 . 
ANDRÉ, Marli. Pesquisa, formação e prática docente. In. ANDRÉ, Marli. (Org). $O$ papel da pesquisa na formação e prática dos professores. 2. ed. Campinas: Papirus, 2002, p. 71-90.

ARAGÃO. R. Desafios na Formação de Professores de Línguas Estrangeira com Novas Tecnologias, UFC, outubro de 2009, p. 59.

AZZARI, E. F.; CUSTÓDIO, M. A. Fanfics, Google Docs... a produção textual colaborativa. In: ROJO, R. (Org.).Escol@ conect@d@: os multiletramentos e as TICs. São Paulo: Parábola, 2013. (Estratégia de Ensino, 40).

BECHARA, E. A norma culta em face da democratização do ensino. Ciclo de conferências A língua portuguesa em debate. Rio de Janeiro, Academia Brasileira de Letras, 2000.

BUENO, Belmira Oliveira. Pesquisa em colaboração na formação contínua de professores. In: BUENO, Belmira Oliveira; CATANI, Denice Barbara; SOUSA, Cynthia Pereira de. (Org.). A vida e o oficio dos professores. 2. ed. São Paulo: Escrituras Editora, 2000.

BRASIL. Base Nacional Comum Curricular. Ensino Médio. Brasília: MEC/SEB, 2018, p. $480-490$.

Orientações Curriculares para o Ensino Médio - Linguagens, Códigos e suas Tecnologias. Brasília: MEC, 2006, p. 21-33.

COPE, B.; KALANTZIS, M. Multiliteracies: literacy learning and the design of social future. New London Group. Routledge, 2000.

; __ Language education and multiliteracies. In: HORNBERGER, N. H.

(Org.). Encyclopedia of language and education, v.1. New York: Springer, 2008, p. 187 - 199.

CUPANI. A. Filosofia da Tecnologia: um convite. 3. ed. Florianópolis: Editora da UFSC, 2016, p. 12 a 205.

FOUCAULT, M. Tecnologias del Yo, Barcelona: Piados Ibérica, 1995, p. 322 a 325.

FREIRE, Paulo \& ILLICH, Ivan. Dialogo: análisis crítico de la "desescolarización" y "concientización" en la coyuntura actual del sistema educativo. Buenos Aires: Ediciones Busqueda, 1975, p. 26 - 92.

FREIRE, Paulo. Educação como prática da Liberdade. Rio de Janeiro; Paz e Terra, 1980.

GORZONI, Sílvia de Paula e DAVIS, Claudia. O conceito de profissionalidade docente nos estudos mais recentes. Cad. Pesqui.[online]. 2017, vol.47, n.166, pp.13961413. Disponível

em http://www.scielo.br/scielo.php?pid=S010015742017000401396\&script=sci_abstract\&t lng=pt. Acesso em 13 de dez de 2018.

http://www.concordancia.letras.ufrj.br. Acesso em abril de 2017

KLEIMAN, Angela (org.) A formação do professor-perspectiva da linguística aplicada. Campinas, SP: 2001, p. $110-135$.

LISPECTOR. Clarice. Felicidade Clandestina. Ed. Rocco. Rio de Janeiro, 1998, p. 160. NÓVOA, António (Org.) Os professores e sua formação. Lisboa: Don Quixote, 1997, p. 25 e 26.

PAIVA, V. M. O. e. Ensino de língua inglesa no ensino médio: teoria e prática. São Paulo: Edições SM, 2012, p. 58-76.

PENNYCOOK, A. A. Critical Applied Linguistics: a critical introduction. Mahwah, NJ: Lawrence Erlbaum Associates, 2001, p. 82-101

PERRENOUD, Phillipe et al. 10 novas competências para ensinar. Porto Alegre: ArtMed, 2000, p. 23-34. 
PERRENOUD, Phillipe et al. As competências para ensinar no século XXI: a formação dos professores e o desafio da educação. 1. ed. Porto Alegre: ARTMED, 2002, p. 176.

RAUSCH, Rita Buzzi. Professor-pesquisador: concepções e práticas de mestres que atuam na educação básica. Revista Diálogo Educacional, Curitiba, v. 12, n. 37, 2012, p. 701-717.

ROJO, Roxane; MOURA, Eduardo. Multiletramentos na escola. São Paulo: Parábola Editorial, 2011, p. 03.

(org.). Escol@ conectada: os multiletramentos e as TICs. São Paulo: Parábola, 2013, p. 194 e 195.

e BARBOSA Jacqueline P. Hipermodernidade, multiletramentos e gêneros discursivos. São Paulo: Parábola Editorial, 2015, p. 123 a 135.

SANCHO, Juana Maria. De TIC a TAC, El difícil tránsito de una vocal. Revista Investigación en La Escuela, n. 64, 2008, p. 19-30.

SANTAELLA, Lucia. A estética política das mídias locativas. Nómadas no. 28. Instituto de Estudios Sociales, Bogotá, 2008, p. 128-137.

SANTANA. Manoela Oliveira de Souza. (Des)encontros entre as OCEM e as práticas textuais com blogs no ensino e aprendizagem de línguas. Dissertação de Mestrado. UESC, BA, 2013.

SANTOS, Edméa. Educação online: cibercultura e pesquisa-formação na prática docente. Tese (Doutorado em Educação) - Faculdade de Educação, Universidade Federal da Bahia, FACED-UFBA, Salvador, 2005. Disponível em: $<$ http://api.ning.com/files Tese final. Edmea.pdf>. Acesso em: 05 de dezembro de 2018. SCHÖN, Donald. Formar professores como profissionais reflexivos. In: NÓVOA, Antônio (Org.). Os professores e sua formação. Lisboa: Publicações Dom Quixote, 1992.

SILVA. Simone Bueno Borges da. e SILVA. Ferreira Laureci. Etnografia e Autoetnografia na Formação de Professores. In KLEIMAN. Ângela B. e ASSIS. Juliana Alves (orgs). Significados e ressignificações do letramento: desdobramentos de uma perspectiva sociocultural sobre a escrita. Campinas São Paulo: Mercado das Letras, 2016, p. 228.

SILVA. Tadeu Tomaz da. Documentos de Identidade: uma introdução as teorias do currículo. $3^{\mathrm{a}}$ ed. Belo Horizonte: Autêntica, 2010, p. 140.

TARDIF, M. Saberes docentes e formação profissional. Petrópolis, R.J.: Editora Vozes, 2002.

VERSIANI. D. Autoenografia: uma alternativa conceitual. Revista Letras Hoje. v. 37 , n. $4.2002 . \quad$ Disponível em http://revistaseletronicas.pucrs.br/fo/ojs/index.php/fale/article/view/14258. Acesso em setembro de 2017.

Recebido em 29 de abril de 2020

Aceito em 11 de junho de 2020 